\title{
EL USO, LA PROPIEDAD Y EL VALOR EN EL DEBATE DE LA LENGUA AMERICANA
}

\author{
Usage, property and value among Latin American linguistic- \\ ideological debates
}

\section{Juan Antonio Ennis}

Universidad Nacional de La Plata

Consejo Nacional de Investigaciones Científicas y Técnicas juanennis@conicet.gov.ar

Resumen: El problema del uso constituye una de las fuentes de discusión y división más sostenidas en el estudio de la lengua. En la historia de los debates ideológico-lingüísticos en torno a la lengua española en América, sobre todo en los relacionados tanto con la formación de un discurso especializado en la materia como con el contexto general de formación y consolidación de los Estados modernos, el problema del uso se revela indesligable del de la propiedad, posibilitando una lectura de cierta economía política de la lengua cuyas reglas o leyes se encuentran allí en disputa. Se propone así una lectura de un corpus integrado por trabajos de Andrés Bello, Miguel Antonio Caro, Rufino José Cuervo y Rudolf Lenz que permita comenzar a delimitar el problema y determinar los alcances de su estudio.

Palabras clave: gramática; uso; valor; América Latina; siglo XIX y comienzos del $X X$.

Abstract: Language usage is probably one of the most discussed issues in language scholarship, and undoubtedly a frequent cause of division among researchers on this field. The usage-question is also present in some instances of the language-ideological debates which took place in Latin America and Spain all along the $19^{\text {th }}$ century and deep into the $20^{\text {th }}$. It reveals itself tightly bound to issues also related to this question in other areas, like property and law, allowing the research on what could be called a linguistic political economy, which rules and laws are being there subjected to debate. This paper proposes to begin the discussion by analyzing some crucial texts of Andrés Bello, Miguel Antonio Caro, Rufino José Cuervo and Rudolf Lenz, which can help to sketch the boundaries and scope of this issue.

Keywords: Grammar; usage; value; Latin America; $19^{\text {th }}$ and early $20^{\text {th }}$ century. 
Consuetudo vero certissima loquendi magistra, utendumque plane sermone, ut nummo, cui publica forma est (Quintiliano, Institutio Oratoria I, 6, III). [La costumbre es la maestra más certera del hablar, y hemos de usar de las voces como de la moneda, que sólo es corriente la que tiene el cuño del día, trad. de I. Rodríguez y P. Sander, Madrid, 1887]

\section{Economías de la lengua nacional}

T $\begin{aligned} & \text { ay un fenómeno propio del lenguaje de la filología histórico-com- } \\ & \text { parativa decimonónica que puede ayudar a explicar la cuestión que } \\ & \text { pretende circunscribirse en este trabajo, precisamente porque se }\end{aligned}$ encuentra en su origen. Se trata de lo que Joseph Errington (2008) ha llamado la "literalización de las metáforas": imágenes comparativas destinadas a explicar ciertos procesos en el ámbito lingüístico que pasan a convertirse en verdaderos artículos de fe científica. De lo que habla Errington, en este caso, es del organicismo y el darwinismo en lingüística. Así, por ejemplo, si la comparación no era ajena a los discursos sobre el lenguaje, y en el prólogo a la Gramática de Andrés Bello se encuentra aún la metáfora anatómica como tal ("Una lengua es como un cuerpo viviente: su vitalidad no consiste en la constante identidad de elementos, sino en la regular uniformidad de las funciones que éstos ejercen", $G C$ viii $^{1}$ ), el lenguaje de la gramática históricocomparativa irá abandonando la metáfora hasta considerar, como August Schleicher, no que las lenguas son como un organismo natural, sino que las lenguas son Naturorganismen (6).

La metáfora económica es recurrente en el discurso sobre la lengua, como en la cita de Quintiliano, donde el valor convenido al signo lingüístico aparece como un contrato social análogo al valor nivelador otorgado a la moneda, aunque en algunos contextos adquiere mayor peso que en otros, particularmente cuando el problema enunciado tiene que ver con la regulación y expansión de la lengua como propiedad, herencia, divisa o mercancía. Así, la impronta económica del discurso de la unidad de la lengua desde el siglo XIX hasta la actualidad es, en sus diversas inflexiones históricas, uno de los rasgos más visibles de continuidad en las políticas de la lengua (y sobre todo del monolingüismo como política), en un discurso secularizador que no deja de exhibir sus tensiones con el religioso ${ }^{2}$. Un buen ejemplo puede encontrarse en el segundo apartado del cambiante prólogo a las Apuntaciones criticas sobre el lenguaje bogotano de Rufino José Cuervo, donde la reflexión sobre la patria y la lengua plantea los límites y problemas de regulación interna que afrontaría cualquier vocación panhispanista:

1 Para las obras de Andrés Bello citadas en este trabajo se utilizarán las abreviaturas GC (Gramática castellana) y $A U$ (Advertencias sobre el uso de la lengua castellana).

2 Una lectura que guarda especial interés en este sentido es la que ofrece el volumen de Joseph Errington. 
De modo pues que, dejando aparte a los que trabajan por conservar la unidad religiosa, aspiración más elevada á formar de todas las razas un solo redil con un solo Pastor, nadie hace tanto por el hermanamiento de las naciones hispanoamericanas, como los fomentadores de aquellos estudios que tienden á conservar la pureza de su idioma, destruyendo las barreras que las diferencias dialécticas oponen al comercio de las ideas $(A C \text { iii })^{3}$.

Este comercio de ideas metaforiza lo que en el prólogo a la Gramática de Bello se denominaba "difusión de las luces", visto en peligro junto a la ejecución de las leyes y la administración del Estado por la diversificación de las lenguas. Más allá de la contigüidad entre lengua y religión, la necesidad de la uniformidad para el comercio de ideas es bastante congruente con la representación del mercado de los intercambios lingüisticos de Pierre Bourdieu (1982), donde el bon usage no implica sólo una jerarquía, sino el consenso en torno a una regla y unidad de valor, la uniformidad necesaria para acordar el valor de cambio otorgado a una unidad de significado. No es así extraño que, para justificar el empleo de las categorías de Pierre Bourdieu, Richard Bauman y Charles Briggs, al comentar el lugar del trabajo de los hermanos Jacob y Wilhelm Grimm en la construcción de una nación y un nacionalismo para Alemania, deban volver sobre esta literalidad de sus metáforas en la formación de la lengua como índice de la nación y la civilización. Así, si bien se preocupan por indicar que la adopción de un léxico economicista y capitalista para el análisis de procesos comunicativos entrańa ciertos riesgos, este caso en particular resulta propicio para el empleo de la noción en cuestión, dado que "uno de los efectos de la obra de los Grimm fue el de tomar formas simbólicas que habían sido escasamente integradas en la economía capitalista e insertarlas de manera sólida en un mercado textual dominado por el capital, infundiéndoles valor en el camino" (Bauman y Briggs 217). Este proceso que hace de la materia prima popular mercancía apta para el mercado de los bienes simbólicos es descripto por los autores del siguiente modo:

Al hacer esto, contribuyeron a transformar formas simbólicas que, según su parecer, habían estado ligadas a ciertos lugares e identidades sociales en particular, de modo tal que pudieran circular en un libre mercado textual. De todos modos, podemos leer este proceso como la extracción de conocimiento de un acervo cultural común y su conversión en capital simbólico que podía ser controlado por ciertas clases en particular, y en mercancías, textos publicados, que podían ser comprados y vendidos en un mercado capitalista $(217)^{4}$.

3 Para las obras de Cuervo se utilizarán las siguientes abreviaturas: AC (Apuntaciones críticas sobre el lenguaje bogotano), DCR (Diccionario de construcción y régimen de la lengua castellana) y CA (El castellano en América)

4 En todos los casos en los que la bibliografía indica un texto en lengua extranjera y no hay indicación específica, la traducción es nuestra. 
Cuando pocos años después, mediando el siglo y desde el sur de América, Domingo Faustino Sarmiento deplore las trabas puestas a la reforma ortográfica en Chile, señalando sus consecuencias en la industria editorial, su argumento responderá al modelo que Bauman y Briggs leen en los Grimm: en su caso, la llamada "soberanía popular" americanista sobre la lengua llevaba consigo el control de un mercado, el de los libros como commodities cuyo espacio de circulación se restringe a partir de la ley de la lengua que dicta el Estado ${ }^{5}$. El lugar del buen uso en Bello, en cambio, el del uso controlado que demarca la primera de las "Nociones preliminares" a la Gramática de 1847, excluye aún del orden de la lengua legítima ese irreductible exterior del Volk: "La gramática de una lengua es el arte de hablarla correctamente, esto es, conforme al buen uso, que es el de la gente educada" ( $G C 1)$. La preocupación entre el buen y el mal uso está presente desde temprano en Bello, y casi siempre en relación con la gramática, la propiedad y la autoridad. De ello dan testimonio sus Advertencias sobre el uso de la lengua castellana dirigidas a los padres de familia, profesores de los colegios y maestros de escuela, aparecidas entre diciembre de 1833 y enero de 1834 en el semanario oficial El araucano, de Santiago de Chile:

En este artículo y en otros que publicaremos sucesivamente, nos proponemos hacer advertir algunas de las impropiedades y defectos que hemos notado en el uso de la lengua castellana en Chile, y que consisten, o en dar a sus vocablos una significación diferente de la que deben tener, o en formarlos o pronunciarlos viciosamente, o en construirlos de un modo irregular ( $A U 17)$.

El buen uso no responde a un purismo vacuo que tiene por objeto la mera conservación de la forma heredada por sí misma, sino que la ley de la gramática es el sostén fundamental de la ley del Estado. En el parágrafo 4 de la Gramática dice:

Siendo la lengua el medio de que se valen los hombres para comunicarse unos á otros cuanto saben, piensan y sienten, no puede menos de ser grande la utilidad de la Gramática, ya para hablar de manera que se comprenda bien lo que decimos (sea de viva voz o por escrito), ya para fijar con exactitud el sentido de lo que otros han dicho; lo cual abraza nada menos que la acertada enunciación y la genuina interpretación de las leyes, de los contratos, de los testamentos, de los libros, de la correspondencia escrita; objetos en que se interesa cuanto hay de más precioso y más importante en la vida social (1).

5 En el mismo año en el cual elogia y recomienda a viva voz la Biblioteca de Autores Ilustres de Rivadeneyra (Velleman 397), advierte sobre la necesidad de proteger un mercado editorial americano aún en ciernes: "En 1847, se ha formado en Madrid la Sociedad de la Publicidad, con dos millones de pesos, y dirigida por el único impresor inteligente con que cuenta la España, Rivadeneira, cuya empresa tiene por campo calculado de explotación la América española, pues que los productos de imprenta tan colosal no hallarían colocación en la sola España” (Sarmiento 399).

anclajeSI XVIII.2 (diciembre 2014) ISSN 1851-4669 I El uso, la propiedad y el valor en el debate de la lengua...:32-47 
La comprensión mutua figura como el primer objetivo que una gramática debería proponerse, aunque de inmediato aparece un segundo afán, que evoca en su estructura el vínculo entre la especialización filológica ("fijar" textos) y la ley como sujeción del orden de los discursos: "fijar con exactitud lo que otros han dicho". Expresarse de manera apropiada significa aquí que la propiedad del enunciado, en cuanto lo "fija" y ajusta así su debida lectura, corresponde a la gramática. La gramática y la ley se encuentran estrechamente entrelazadas, formando un mismo cuerpo (el cuerpo de la nación que el Estado debía crear): para que la ley funcione, hacen falta ciudadanos capacitados para entenderlas y ponerlas en práctica (Jaksić 186). De acuerdo con Elvira Narvaja de Arnoux, no hay aquí contradicción alguna entre gramática y Estado: ambos están inspirados por la misma lógica (279).

\section{La literatura, la norma, la moda y el valor del uso: tensiones entre gramática y filología en Caro y Cuervo}

Similar preocupación a la de Bello mueve también a Miguel Antonio Caro décadas después, y así dará con una traducción erudita, antigua y prestigiosa de esta misma definición: "Quintiliano, tropezando con la dificultad que presenta la variedad de usos, enseña que por uso ha de entenderse el consentimiento de los eruditos, así como en punto de moralidad no hay otra costumbre respetable que aquella en que convienen los buenos" (URL 8). La alusión de Caro remite al mismo pasaje de las Institutiones arriba citado, que en sus últimas líneas pone límites a la consuetudo, uno de los cuatro parámetros para establecer las reglas del habla, junto a la razón, la autoridad y la etimología. Caro dedicará al problema del uso un célebre discurso en la Junta Inaugural de 1881 de la Academia Colombiana. La ocasión no carece de relevancia, dado que la fecha es el 6 de agosto, aniversario de la fundación de Bogotá, traducido por Caro como la celebración del "recuerdo de aquellos hombres de buena fe y sin miedo que trajeron y establecieron la lengua de Castilla en estas regiones andinas" (URL 3) $)^{6}$.

Del uso en sus relaciones con el lenguaje se abre con un deslinde de los antagonistas posibles a una posición que presentará como de mesura epistemológica y política, entre los extremos del materialismo, positivismo, utilitarismo, variantes del otro usual para la argumentación de Caro, y la elucubración filosófica sin asidero práctico ni empírico. Interesa observar en este caso cómo el argumento de Caro opondrá la inconstancia e inasibilidad del uso a la necesidad de la Ley:

Paréceme, señores, análoga en algun modo y paralela á semejantes doctrinas, superficiales y contentadizas, aquella que en el órden literario erige al uso en regla suprema del bien decir, en norma única del lenguaje. Uso es sinónimo de

6 Para la mención de los textos de Caro se utilizarán las siguientes abreviaturas: URL (Del uso en sus relaciones con el lenguaje), $O E$ ("Oración de estudios"), $A B$ ("Don Andrés Bello"), IC ("Ignorancias de la ciencia"). 
costumbre y á las veces de moda: la costumbre, como el interes, como el gusto, es vária, y la moda caprichosa; y modas y costumbres cambian y se diversifican con los lugares y con los tiempos (URL 5).

La de la volatilidad de la moda es una preocupación central de los modernismos y por ello recurrente en todo texto de intervención en la cultura. Desde una perspectiva más condescendiente con la noción de uso (y más cercana a la de Quintiliano), Cuervo también incluía en el prólogo a las Apuntaciones esta salvedad:

Sucede á veces también con el lenguaje como con el vestido: no basta que un vocablo ó giro sea de buena estofa; requiérese además que esté actualmente en uso, pues es ridículo sacar inoportuna é innecesariamente á relucir antiguallas; ni lo es menos acoger luego al punto cuantas extravagancias idea el liviano capricho de la moda (AC ix).

El peligro que impone el uso a la concepción autoritativa, que podríamos llamar tradicional, del lenguaje es el de aquello que escapa al dominio de la autoridad establecida, al orden o al control. Son precisamente problemas como los de la autoridad, la ley, la propiedad y la herencia los que nos pueden permitir recorrer con cierta coherencia la obra de Caro, quien coincide con Bello en la preocupación común y exitosa por la ley y la lengua, y si este había podido plasmarla en una Gramática y un Código civil de profunda y duradera influencia, aquel no sólo se ocupará de disputar ese legado (los textos en torno al centenario de Bello son en este sentido ejemplos extraordinarios de apropiación de una figura y un corpus, donde, por ejemplo, logra situar a Sarmiento nada menos que en el lugar de la barbarie americana) sino que alcanzará similares resultados en la prescripción lingüística y sobre todo en la codificación legal ${ }^{7}$. El impulso secularizador que lleva a Cuervo del polo de la prescripción gramática a la asepsia del rigor filológico, polo de prestigio científico que será más poderoso desde su instalación en París, encuentra su reverso en la constancia del movimiento de Caro, de la redacción de la gramática latina y la orientación de la crítica literaria, al discurso parlamentario, el periodismo político y, sobre todo, la redacción de la Constitución. Para Ángel Rama, en Las máscaras democráticas del modernismo, Caro aparece asimismo como

el más lúcido y coherente expositor del pensamiento conservador de la época. Lo que en otros tratadistas se disfraza con concesiones al espíritu democrático o se

7 Sarmiento pasa en el argumento de Caro al lugar de la barbarie americana que arremete contra la civilización europea, representada por el legado español en Bello, quien recibe el irónico epíteto de "advenedizo" que él mismo aplicaba a los españoles como civilizadores de América. Para hacer más claro el lugar otorgado a Sarmiento, basta con estas líneas, extraídas del argumento mencionado: "la barbarie indígena, para combatir a la civilización forastera, hace uso de armas que no son suyas, sino usurpadas a su gloriosa enemiga, valiéndose de la cátedra y de la imprenta" (Caro $A B$ 110-111). 
amalgama con tradiciones liberales americanas, en él adquiere un rigor estimable, una exposición categórica a partir de una adhesión sin fisuras al catolicismo militante de la lucha antipositivista (18-19).

En 1886 - como subraya Fernando Vallejo en su última novela, El cuervo blanco (2012)—, mientras Cuervo publica en París el primer volumen de su desmesurado Diccionario de construcción y régimen, Caro publica y pone a funcionar - por largo tiempo- la obra de su vida, la constitución conservadora de Colombia: "Salió el flamante tomo I de la imprenta de Bourlotton en noviembre de 1886, año de la Constitución de Colombia que los degenerados de la Regeneración de Núñez, inspirados por Caro, en mala hora emitieron. Yo nací bajo su oscuro manto" (Vallejo 146). Hay en esa coincidencia al mismo tiempo un principio de escisión, por el que la capitalización del uso popular se hará así más próxima en el Cuervo del $D C R$ al modelo de Grimm que al de Caro. Esto no significa que lo "vulgar" devenido "popular" no deje de ocupar un margen residual, de escaso valor y menor influencia para determinarlo frente al control del mercado del uso legítimo, sino que ese margen deja ahora de ser residuo para convertirse en materia prima hasta entonces no explotada, reserva orgánica a la que el experto aporta un plusvalor al descifrar su carácter de expresión incontaminada de la nacionalidad:

El elemento popular aparece en el Diccionario no sólo como la materia prima del idioma, germen que crece al aliento de la literatura, sino que va representado por una muchedumbre de voces, metáforas, locuciones y refranes que acaso jamás se han estampado en los libros. Ni podrá excluirse tal elemento: el cuerpo de la nación, el pueblo formó la lengua, el pueblo conserva fielmente el depósito tradicional, lejos de influencias extrañas é inaccesible al incierto vaivén de la moda (Cuervo DCR XXVIII).

La metáfora económica (la de la materia prima del idioma) va asociada directamente a la metáfora orgánica de la nación ligada a la lengua, preservando la prudente distancia ante el amenazante fenómeno de la moda. El uso aparece como un problema en la medida en que la reflexión filológica debe justificar su utilidad. No por casualidad esa materia prima se representa por una muchedumbre de voces. El problema de la muchedumbre o de la masa, cuando circunstancialmente se relaciona con la historia de la lengua, en el "Prólogo para franceses" que en 1937 escribe José Ortega y Gasset para La rebelión de las masas, recae una vez más en una forma de la comparación con el dinero. Ortega lamenta la corrupción de la "sabrosa complejidad indoeuropea" en el latín vulgar, suplantada por "un habla plebeya, de mecanismo muy fácil, pero a la vez, o por lo mismo, pesadamente mecánico, como material; gramática balbuciente y perifrástica, de ensayo y rodeo, como la infantil" (63). Lejos de la devoción romántica por el Volk, observa la devaluación de esa forma heredada: "Los vocablos parecen viejas monedas de cobre, mugrientas y sin rotundidad, como hartas de rodar 
por las tabernas mediterráneas" (63).

En el prólogo de 1886 a la Gramática latina de Caro y Cuervo se lee: "Las gramáticas explican la forma, y requieren el auxilio de los Diccionarios, que ordenan la materia" (xvi), y en este sentido puede verse cómo, a pesar de estas distancias, el discurso de Caro procura apropiarse de la división del trabajo y la distribución del capital simbólico que organiza la escuela filológica moderna para someterla simultáneamente a un orden que él mismo llamaría tradicional. Volviendo a las resonancias posibles de la cita inicial, es la forma publica el objeto y fin último de la preocupación lingüística, política y pedagógica de Caro.

Por eso mismo, Del uso... procura dar con la racionalidad de un sistema que se traduzca en las necesidades prácticas de una razón filológica que se subordine a la razón de Estado, en una Colombia que necesita incorporarse a la lógica del capital global (en ese sentido los Escritos económicos de Caro son de gran interés), pero sin dejar de abrazar un tradicionalismo antisecular. Por eso la escisión entre ciencia y política, la separación de las esferas de lo público le resultará potencialmente nociva. Así, "la teoría que principia por fijar el uso como única norma del bien decir, acabará mal que pese á sus sostenedores, si es lógica en sus conclusiones, negando toda norma racional en materia de lenguaje" (Caro URL 6). Si el uso es lo variable y la norma equipara racionalidad con permanencia, el tiempo y la persona de esa racionalidad son las del enunciador del discurso. En este sentido, es notable el modo en el cual Caro organiza la distribución del patrimonio que representa la lengua entre el "pueblo" y "los literatos y eruditos": el primero sólo es consciente de su lengua cuando la misma se ve amenazada, "[f]uera de estos casos excepcionales, el pueblo habla la lengua que ha recibido por tradición, sin conocer ni sospechar siquiera la clase de tesoro de que dispone, y la poetiza ó la aplebeya sin conciencia de sus actos". Los segundos no pueden excusarse en el uso, dado que son quienes descubren "las leyes del lenguaje", al que "no sólo [...] manejan por mero instinto de imitación", sino que hacen uso de él, "como un instrumento cuya forma y fines científicamente conocen" (URL 7). Caro, que no desconoce los métodos y teorías de las filologías clásica y moderna, reproduce la ley de la relación entre la materia prima popular y la conversión en mercancía (la ley de la separación, entre el uso y el valor de cambio, entre la praxis y la codificación científica), se interna en un punto sensible de sus disputas, apartándolo de la lógica que el biologicismo del siglo le había impuesto y ocupándose de revertir el resultado habitual de sus argumentos, el de la condena al prescriptivismo tradicional, al preguntar: "¿Y cómo había de elevarse el estudio de las lenguas á la categoría de ciencia, y entre ciencias excelentísima, si el lenguaje no reconociese más norma que el uso, arbitrario á las veces y siempre variable?" (URL 7). Ni los intentos de desarrollar e imponer una lengua universal, ni aquellas teorías (como las de Johann G. Herder, Jacob Grimm, Heymann Steinthal o Ernst Haeckel) que hacen de la lengua el índice de lo humano podrían resistir la soberanía del uso, pero nadie se habría atrevido a poner en claro esta limitación, los filósofos por considerar los de la lengua 
problemas menores, los filólogos porque "repiten a coro que el uso es norma del lenguaje" (Caro URL 8).

La modernización antimoderna de Caro hace de cada discusión una política entre tradición hispano-católica y Modernidad europea. Sus embates se dirigen a los fundamentos de la amenaza en cuyo mundo, sin embargo, cree poder ingresar sin someterse a su retórica: así como al introducir la Gramática latina puede aprovechar el repaso de las escuelas filológicas europeas para poner en cuestión el libre examen protestante ${ }^{8}$, aprovechará ocasiones como la que le ofrece la discusión sobre la "naturaleza y funciones de la moneda así como su circulación" para impugnar nada menos que a René Descartes y a George Berkeley y, de alguna manera, dar cuenta de su conciliación entre tradición hispano-católica y progreso técnico (Caro IC 6).

En el cuarto apartado de Del uso..., Caro parte de una definición preliminar del uso como "la forma que toma una lengua y el curso que lleva en boca de las gentes que la hablan, entregada al instinto natural y á la imitación irreflexiva, y libre de la influencia directa de los libros" (URL 22). De allí es, del "uso, reciente o antiguo" que "reciben siempre la materia prima los artífices de la lengua" (24). ¿Quiénes son estos artifices de la lengua? Más adelante se hará explícito: gramáticos y escritores.

La organización entre materia prima y valor de cambio contribuirá también a dirimir el área de competencia de estos últimos y los filólogos. Ponderando el reciente desarrollo de los estudios históricos sobre las lenguas románicas en su evolución desde el latín, a partir de una tipología de los períodos evolutivos de la lengua establecida anteriormente - que divide este desarrollo en un periodo "bárbaro o anteclásico; otro literario o clásico; y otro, en fin, crítico o post-clásico" (Caro URL 29)—, encontrará el meollo para incidir en lo que ya era y devendría en grado aún mayor, uno de los puntos más sensibles en las disputas por la lengua nacional y la unidad de la lengua en Hispanoamérica: la razón científica que indicaba la necesaria fractura de la lengua con su imperio. Así como sucedió con el latín, debería suceder con el español, había sido ya el argumento de August Friedrich Pott al leer las Apuntaciones de Cuervo, que éste luego haría propio (cfr. Ennis y Pfänder):

La influencia de la que fué metrópoli va debilitándose cada día, y fuera de cuatro o cinco autores cuyas obras leemos con gusto y provecho, nuestra vida intelectual se deriva de otras fuentes, y carecemos pues casi por completo de un regulador que garantice la antigua uniformidad (Cuervo CA 26).

8 "Curiosa inconsecuencia ofrecen en esta materia las gentes letradas protestantes, de regiones septentrionales, porque al paso que publican sin notas los oscuros libros orientales de la Sagrada Escritura, fundándose en el principio del libre examen, reconocen prácticamente en lo profano la falsedad de semejante teoría, con el laudable empeño que ponen en anotar y explicar los clásicos griegos y latinos" (Caro y Cuervo ix-x). 
El lugar de publicación es uno marginal para la actividad filológica $-\mathrm{y}$ en apariencia también para la literaria- pero en especial relevante, sobre todo en la época en que está escrito: se trata de una carta-prólogo al poema Nastasio, del poco recordado poeta argentino residente en París, Francisco Soto y Calvo. Muy probablemente, este texto debería tener un lugar de privilegio en la lista de aquellos innumerables prólogos finiseculares que, como apunta Julio Ramos en las primeras páginas de su indispensable Desencuentros de la modernidad en América Latina, "revelan la crisis del sistema cultural anterior" (8). La intervención de Cuervo (que lo conducirá a la conocida polémica con Juan Valera, autor a su vez de una de las cartas-prólogo fundamentales del Modernismo Hispanoamericano) se manifiesta así como una variante particularmente efectiva de esto que podríamos llamar el "prólogo modernista", cuya pieza dilecta en el trabajo de Ramos la constituye el de Martí al "Poema del Niágara" de Antonio Pérez Bonalde (como en el caso de Cuervo, un comentario célebre para un poema olvidado), que interviene de manera polémica en la sanción de los aspectos más salientes de la crisis moderna (de modernización) del sistema de valores tradicional, en el cual

la literatura - modelo, incluso, del ideal de una lengua nacional, racionalmente homogeneizada - había sido el lugar — ficticio, acaso — donde se proyectaban los modelos de comportamiento, las normas necesarias para la invención de la ciudadanía, los límites, las fronteras simbólicas, el mapa imaginario, en fin, de los estados en vías de consolidación" (Ramos 8).

El modelo en crisis es aquel que ofrecía Andrés Bello y sostenía Caro, el de la gramática como arte del cuidado de la lengua común, homogénea y hegemónica, instrumento privilegiado de la difusión de las luces, garante de la fijación y continuidad de las leyes, de la identidad de la palabra. La literatura, en el dato que ofrece la necesidad del glosario en el poema de Soto y Calvo, ya no es el modelo a seguir para reducir la diferencia, sino el lugar de su constatación.

\section{El uso, sus utilidades y sus límites (sobre la ley y la ciencia)}

En una carta en la que brindaba a Cuervo su apoyo en la disputa con Valera, Rudolf Lenz pone al colombiano del lado de la comprensión científica de la lengua, integrando la polémica en una que él mismo hacía tiempo afrontaba en Chile (Ennis):

En materia de lingüística es imposible convencer a un literato porque estos no admitirán nunca que no comprenden más de lingüística que el arquitecto de geología, aunque el literato use palabras y el arquitecto piedras (Lenz en Romero 19).

Lenz trabaja, desde la lingüística y la etnografía, y sobre todo desde la discusión en torno a qué sea la gramática, en aras de la capción del uso, de su 
capitalización en un terreno que fomenta su autonomía en el rechazo de la utilidad, de los fines ajenos a sí mismo:

En jeneral he juzgado inútil comprobar la existencia de una palabra por muchas citas de frases entresacadas de las novelas de costumbres, porque solo relativamente pocas palabras se podrian demostrar de este modo. Muchísimas de las palabras que rejistro nunca se habrán impreso, muchas quizás nunca se han escrito, pues para las voces que no se encuentran en los léxicos anteriores, fuera de los términos de historia natural, mi principal fuente es el uso oral (Lenz EI 31) .

A este uso oral se opone el uso normado, que responde a una definición que se identifica también como a- o pre-científica de la gramática —el "arte de hablar de acuerdo al buen uso" de Bello_- y que opondrá a la idea de la gramática como ciencia descriptivo-explicativa:

Pues bien, lo que el naturalista botánico es para el reino vejetal, lo es el lingüista para las lenguas en su totalidad; al jardinero correspondería el literato que se deleita en la armonía de un verso clásico, que estudia las particularidades del estilo de tal o cual autor i establece las reglas para el "correcto uso gramatical" de tal o cual palabra o construccion (Lenz EI 11).

El valor de la gramática no está ya en su carácter de ciencia orientada a la praxis (recte loquendi scientia, con Quintiliano), sino, sobre todo a partir de las innovaciones aportadas por la filología decimonónica alemana, lo que la hace ciencia es su desinterés: el estudio de la lengua por la lengua misma. El primer historiador de la disciplina, Theodor Benfey, lo formula, precisamente, como una negación del uso, al describir por contraste el estudio no científico de la lengua, cuando se aprenden lenguas "no sólo por su propio interés, sino para su uso". El uso, en este caso, como uso de una segunda lengua, es decir, como fin práctico [ihres Gebrauchs wegen, dirá], se diferenciará del estudio de las lenguas por sí mismas [um ihrer Selbst Willen] (Benfey 1). Lo que señala Lenz como problema del estadio pre-científico del saber sobre la lengua en Chile tiene que ver tanto con esta aversión por el uso no legítimo como con la equivalente incomprensión de su utilidad, de su valor capitalizable en tanto imagen filológica del pasado (Errington 48-69):

Como noté luego que la gente culta, sobre todo los profesores de castellano, no tenían ningún interés por el estudio de la "jerigonza corrompida de la plebe", porque simplemente despreciaban porque no comprendían que el estudio de los dialectos vulgares da los materiales más interesantes para comprender la evolución histórica del lenguaje humano (Lenz DH 17).

9 Para las obras de Lenz, se utilizarán las siguientes abreviaturas: EI (Los elementos Indios en el castellano de Chile) y $\mathrm{DH}$ ("Dialectología hispanoamericana"). 
La lengua del otro (del indio, del huaso, del negro en el caso del papiamento) ofrece la imagen de un estadio anterior, inferior en la evolución con respecto a la lengua propia (Ennis). Interesa al estudio de la lengua en sí misma, porque en sí misma carece de valor para los fines prácticos: no es capitalizable en el mercado lingüístico, pero sí valiosa, separada del uso, en el campo de la lingüística, y aquí nuevamente definiéndose en relación con el punto de llegada de la lengua prestigiosa.

Es así el desinterés, el valor científico desprendido del uso político —al menos en su retórica, al menos del uso político que él pretendía darle- lo que Caro identificaba como amenaza y ponía en la base de su pensamiento pedagógico. Ejemplo ilustrativo de ello ofrece la alusión a Élisée Reclus en la "Oración de estudios":

Jamás, jamás os diré con aquellos que a título de propagar las luces fanatizan la instrucción, que la ciencia, en su más alto grado, ni menos cuando es incompleta y superficial, basta por sí sola a formar buenos ciudadanos. No: el saber no es la virtud, ni engendra la virtud, ni suple la virtud. [...] y puede haber un erudito, un sabio, con cuyo nombre deben estar familiarizados entre vosotros cuantos hayan adelantado en el estudio de las ciencias geográficas, que con la misma mano con la que traza la descripción de la capital de Francia, haya tal vez empuñado la tea comunista para incendiar sus monumentos (OE 97).

La intervención mencionada en el debate filológico en torno a la unidad de la lengua residirá en la valoración del aporte de la ciencia para explicar lo documentado, relativizando su valor predictivo ${ }^{10}$, que por el contrario entra en el terreno de la literatura y la gramática como asuntos de Estado, como apertura a la discusión de la necesidad de la unidad de la lengua en Hispanoamérica. El carácter forzoso de la ley natural hace a la necesidad de una legislación homogénea y efectiva, a una jerarquía clara entre el uso legítimo y el ilegítimo y sus usuarios: "La descomposicion de una lengua entregada al uso, y su multiplicación en dialectos, es ley natural, cuyo cumplimiento sólo se aplaza o se elude por la accion que ejerce la literatura sobre el lenguaje vulgar. Es la literatura la sal del lenguaje, el único poder que neutraliza é impide la accion disolvente del uso" (Caro URL 47-48).

El uso lingüístico, que tiene la misma condición que la costumbre o la moda, debe ser como ellas limitado, encaminado por una razón superior a la irracionalidad vulgar. Que el cambio operado por el uso en edades bárbaras

10 "Nace de aquí que, si bien de los resultados es permitido ascender, por via de recomposicion, al origen, y confrontados diversos idiomas congéneres se ha ensayado, y ensayarse puede, con buen éxito la reconstrucción de la lengua madre, no de igual manera trazará el filólogo la forma circunstanciada de futuros dialectos. Como en la historia del mundo, en la del lenguaje la ciencia anuncia bienes ó males, prosperidades ó catástrofes, pero en globo; la experiencia recomienda recursos eficaces para remediarse del daño que amenaza, pero sin responder a las contingencias; porque la espontaneidad traviesa, hurtándose al análisis, se encarga de desbaratar los cálculos fundados en el cumplimiento riguroso de leyes naturales" (Caro URL 35). 
tenga la sabiduría de una ley (30), no significa que esta sabiduría sea en sí una ley natural, y por ello había establecido que "concediendo al uso todo el poderío y los privilegios todos que de derecho se le deben, todavía no es el árbitro supremo, única norma del lenguaje" (26). En este sentido, las leyes del uso se asociarán a la arbitrariedad, el capricho y la imprevisibilidad: "la razon en que apoya sus decretos, es aquella sinrazón porque sí de los nińos, de los necios y de los tiranos" (32). Es por ello que "Gramáticos y escritores no rompen en lucha abierta con el uso, y aún se ven obligados a contemporizar con muchas de sus exigencias; mas todavía ejercen sobre él indisputable autoridad, lo dirigen, lo depuran, acaudalando y embelleciendo la lengua" (27). Si el pueblo produce la materia prima, es al letrado al que corresponde otorgarle valor: valor de cambio que permite "asimilar lo ajeno sin pérdida de lo propio" (29). Así, la ley natural será el fundamento de una norma jurídica: "Leyes solicito, cualesquiera que sean, porque legalidad es forma de justicia, y justicia realización de derecho; y cuanto mas antigua la ley que descubro, más me satisface, porque por su antigüedad mido la alteza de su origen y lo benéfico de su institución” (33).

\section{Cierre}

Así como la gramática, produciendo un hablar sin denotación, ha aislado del discurso algo así como una lengua, y el derecho, suspendiendo el uso y los hábitos concretos de los individuos, ha podido aislar algo así como una norma, en todo ámbito el paciente trabajo de la civilización procede separando la praxis humana de su ejercicio concreto (Agamben 78).

Difícilmente pueda completarse un panorama de la historia de la lengua en América Latina sin tener en cuenta la serie de procesos históricos que instalan el horizonte de la nación monolingüe como proyecto de Estado y el modo en el cual el discurso, las políticas sobre la lengua se ubican en el centro de las estrategias de las élites dominantes para la construcción de hegemonía, es decir, entre otras cosas, para hacer de ese horizonte un artículo del sentido de lo común. Pero no se trata sencillamente de observar una prehistoria prescriptivista desde la racionalidad descriptiva de una disciplina ya madura, sino antes bien de ver cómo la separación, sea bajo la forma de la exclusión o de la apropiación y capitalización, genera el objeto y su ley, y cómo puede observarse ese proceder en la relación con la propiedad y el uso, con la asignación de valor en la economía de la lengua.

Este trabajo pretende avanzar en un terreno difícil de asir y delimitar como el de la propiedad de la lengua, objeto de largas y renovadas discusiones, desde un enfoque sobre la historia de sus discusiones, que permita observar cuáles son los mecanismos que hacen que una lengua, por definición (cuando se convierte en una lengua), como cualquier otra mercancía, sea apropiable, esto es, ajena ${ }^{11}$.

11 Para una mirada reciente sobre el problema ver Ciapuscio. 
Una de las principales dificultades que se afrontan en este caso es la de desplegar en un espacio limitado un conjunto representativo de materiales que al mismo tiempo puedan ser articulados críticamente para dar sustento al enfoque teórico que aquí quiere exponerse. Este se funda en algo que ya sostenía Michel Foucault en el pasaje de Las palabras y las cosas dedicado a la emergencia de la gramática histórico-comparativa, al afirmar que no es una mera modificación en el tratamiento de unos datos a la vez ampliados por el "descubrimiento" del sánscrito y la hipótesis del indoeuropeo lo que hace de los textos fundacionales de la disciplina el umbral de una nueva episteme, sino que fue "todo el modo de ser del lenguaje (y del nuestro) el que se modificó a través de ellos" (275). Más recientemente, Errington ha examinado cómo esa modificación en el ser mismo del lenguaje se opera a nivel global, demostrando que la lingüística moderna sólo puede ser pensada como saber colonial, y de qué modo la expansión científica del saber de la lengua continúa, secularizándola, la labor de los gramáticos misioneros en los primeros siglos de la conquista y colonización de América, labor que se define como apropiación, separación, puesta en valor y devolución de la lengua del otro, ya traducible y comparable en el saber occidental. En suma, de lo que se trata no es sólo de recopilar el anecdotario interno de una disciplina más allá del núcleo duro de su evolución teórica, sino de postular que difícilmente pueda pensarse una historia de la lengua sin una historia de su codificación, de las formas de apropiación y cristalización de la praxis lingüística.

\section{Referencias bibliografícas}

Agamben, Giorgio. Estado de excepción. Homo Sacer II, I. Buenos Aires : Adriana Hidalgo, 2004.

Bauman, Richard y Charles L. Briggs. Voices of Modernity. Language Ideologies and the Politics of Inequality. Cambridge: Cambridge University Press, 2003.

Bello, Andrés. Gramática de la lengua castellana destinada al uso de los americanos. París: Roger \& Chernovitz, 1914.

-. Advertencias sobre el uso de la lengua castellana. La Plata: Ministerio de Educación de la Provincia de Buenos Aires, 1956.

Benfey, Theodor. Geschichte der Sprachwissenschaft und orientalischen Philologie in Deutschland. München: Literarisch-artistischer Anstalt der J. G. Gotta'schen Buchhandlung, 1866.

Bourdieu, Pierre. Ce que parler veut dire. L'économie des échanges linguistiques. París: Fayard, 1982.

Caro, Miguel Antonio. Del uso en sus relaciones con el lenguaje. Discurso leido ante la Academia Colombiana en la Junta Inangural del 6 de agosto de 1881. 
Bogotá: Imprenta de Echeverría Hnos., 1881.

—. "Oración de estudios". Obras completas, tomo III. Bogotá: Imprenta Nacional, 1921. 96-104.

—. "Don Andrés Bello". Obras completas, tomo III. Bogotá: Imprenta Nacional, 1921. 105-162.

—. "Ignorancias de la ciencia". Escritos sobre cuestiones económicas. Bogotá: Imprenta del Banco de la República, 1943. 3-6.

Caro, Miguel Antonio y Rufino José Cuervo. Gramática latina para el uso de los que hablan castellano. 1867. Bogotá: Imprenta Nacional, 1915.

Ciapuscio, Guiomar. “La lengua, ¿Tiene dueño?”. Ex libris 1 (2013): 406-412.

Cuervo, Rufino José. Apuntaciones críticas sobre el lenguaje bogotano. París: Roger et Chernvitz, 1914. $6^{\circ}$ edición.

-. Diccionario de construcción y régimen de la lengua castellana, tomo I. París: Roger \& Chernovitz, 1886. Reimpreso Bogotá: Instituto Caro y Cuervo, 1953.

-. El castellano en América. Polémica con Juan Valera. Bogotá: Instituto Caro y Cuervo, 2004.

Ennis, Juan. "Rudolf Lenz en la encrucijada criolla". Signo \& Seña 22 (2012): 181-214.

Ennis, Juan y Stefan Pfänder. "La unidad de la lengua y la irrupción de la lingüística". Revista Argentina de Historiografia Lingüistica I.2 (2009): 175-194.

Errington, Joseph. Linguistics in a Colonial World. A History of Language, Meaning and Power. London \& New York: Blackwell, 2008.

Foucault, Michel. Las palabras y las cosas. Una arqueología de las ciencias humanas. Buenos Aires: Siglo XXI, 2002.

Jaksić, Iván. Andrés Bello, la pasión por el orden. Santiago: Editorial Universitaria, 2001.

Lenz, Rodolfo. Los elementos indios del castellano de Chile. Estudio lingüistico $i$ etnolójico. Primera parte. Diccionario etimolójico de las voces derivadas de lenguas indijenas americanas. Santiago: Imprenta Cervantes, 1910.

-. "Dialectología hispanoamericana". El español en Chile. Trabajos de Rodolfo Lenz, Andrés Bello y Rodolfo Oroz. Alonso, Amado y Raimundo Lida eds. Buenos Aires: Instituto de Filología, 1940.

Narvaja de Arnoux, Elvira. Los discursos sobre la nación y el lenguaje en la formación del Estado (Chile, 1842-1862). Estudio glotopolitico. Buenos Aires: Santiago Arcos, 2008. 
Ortega y Gasset, José. La rebelión de las masas. Madrid: Espasa-Calpe, 2006.

Rama, Ángel. Las máscaras democráticas del modernismo. Montevideo: Fundación Ángel Rama, 1985.

Ramos, Julio. Desencuentros de la modernidad en América Latina. México: Fondo de Cultura Económica, 1989.

Romero, Mario Germán. "Prólogo". Cuervo, Rufino José. El castellano en América. Polémica con Juan Valera. Bogotá: Instituto Caro y Cuervo, 2004. $15-22$.

Sarmiento, Domingo Faustino. Educación popular. Obras Completas XI. Buenos Aires: Luz del día, 1950.

Schleicher, August. Die Darwinsche Theorie und die Sprachwissenschaft: Offenes Sendschreiben an Herrn Dr. Ernst Häckel. Weimar: Böhlau, 1863.

Vallejo, Fernando. El cuervo blanco. Buenos Aires: Alfaguara, 2012.

Velleman, Barry. "Domingo F. Sarmiento y la función social de la lengua". History of Linguistics in Spain II. Koerner, E.F.K. Y Niederehe, Hans-Josef eds. Amsterdam y Philadelphia: John Benjamins, 2001. 391-405.

Fecha de recepción: 29/07/2013 / Fecha de aceptación: 22/10/2013 